\title{
Changes in respiratory virus infection trends during the COVID-19 pandemic in South Korea: the effectiveness of public health measures
}

\author{
Ji Young Park ${ }^{1}$, Hwan Il Kim¹, Joo-Hee Kim , Sunghoon Park ${ }^{1}$, Yong Il Hwang ${ }^{1}$, Seung Hun Jang ${ }^{1}$, \\ Yong Kyun $\mathrm{Kim}^{2}$, and Ki-Suck Jung ${ }^{1}$
}

Divisions of ${ }^{1}$ Pulmonary, Allergy and Critical Care Medicine and ${ }^{2}$ Infectious Diseases, Department of Internal Medicine, Hallym University Sacred Heart Hospital, Anyang, Korea
Received: January 12, 2021 Revised : March 18, 2021 Accepted: May 10, 2021

\section{Correspondence to}

Ji Young Park, M.D.

Division of Pulmonary, Allergy and Critical Care Medicine,

Department of Internal Medicine, Hallym University Sacred Heart Hospital, 22 Gwanpyeong-ro 17obeon-gil, Dongan-gu, Anyang 14068, Korea Tel: +82-31-380-3715

Fax: $+82-31-380-3973$

E-mail: evanoo7@naver.com https://orcid.org/0000-00026533-4656
Background/Aims: Studies on the effectiveness of public health measures to prevent respiratory virus transmission in real-world settings are lacking. We investigated the effectiveness of universal mask use and adherence to other personal preventive measures on the changing viral respiratory infection patterns during the coronavirus disease 2019 (COVID-19) pandemic.

Methods: Data were extracted from the South Korean National Respiratory Virus Sentinel Surveillance System. During the COVID-19 pandemic, a cross-sectional survey on adherence to personal preventive measures was conducted. Additionally, the number of subway passengers was analyzed to estimate physical distancing compliance.

Results: During the pandemic, adherence to personal preventive measures significantly increased, particularly indoors and on public transportation. Respiratory virus trends were compared based on laboratory surveillance data of 47,675 patients with acute respiratory infections (2016 to 2020). The 2019 to 2020 influenza epidemic ended within 3 weeks, from the epidemic peak to the epidemic end, quickly ending the influenza season; with a 1.8- to 2.5-fold faster decline than in previous seasons. Previously, the overall respiratory virus positivity rate remained high after the influenza seasons had ended (47.7\% to $69.9 \%)$. During the COVID-19 pandemic, this positive rate, $26.5 \%$, was significantly lower than those in previous years. Hospital-based surveillance showed a decreased number of hospitalized patients with acute viral respiratory illnesses.

Conclusions: This study suggests that high compliance to the use of personal preventive measures in public might reduce the incidence of all respiratory virus infections and its hospitalization rates, with no additional quarantine, isolation, or contact screening.

Keywords: COVID-19; Disease outbreaks; Preventive measures; Masks

\section{INTRODUCTION}

The novel beta-coronavirus, severe acute respiratory syndrome coronavirus 2 (SARS-CoV-2), first reported in Wuhan, China in 2019, spread to the neighboring Asian countries and was declared a pandemic in March 2020 [1]. On January 20, 2020, the first case of coronavirus disease 2019 (COVID-19) was confirmed in Korea. 
The Korean Centers for Disease Control and Prevention (KCDC) raised the infectious disease alert level on January 27,2020 , and provided strong recommendations on coughing etiquette and hand washing [2]. Moreover, Koreans have an increased interest in the use of personal protection [3]. This is because of the quarantine failure experienced in the country during the 2015 Middle East respiratory syndrome coronavirus (MERS-CoV) epidemic. This led to increased public awareness on the issue of respiratory virus infections [4-6]. Hence, during pandemics, most people in Korea wear masks while using public transport and at public gatherings, leading to an increasing rate of people wearing masks in daily life. Furthermore, given the growing concern with fine dust pollution, including Asian dust, Koreans have generally accepted the use of masks (against particulate pollution) in daily life [7].

The influenza season in Korea occurs during each winter, like in other countries with temperate climates [8]. In community settings, no additional isolation or contact screening is required for patients with flu or respiratory infections [9]. In the 2019 to 2020 influenza season, respiratory physicians in Korea observed a rapid decrease in the incidence of flu-like symptoms in the population and an increase in the incidence of confirmed COVID-19 cases. To prevent the transmission of important emerging infectious diseases, such as COVID-19, there is an urgent need to evaluate the effectiveness of prevention measures in use by all the community members in high-risk areas. Therefore, we investigated the effectiveness of the use of and adherence to personal preventive measures (including universal mask use) on the changing patterns in seasonal respiratory virus infections, across Korea, during the COVID-19 pandemic.

\section{METHODS}

To evaluate the changes in the prevalence and patterns of influenza and respiratory viruses during the COVID-19 outbreak, national surveillance data from the KCDC were analyzed. The KCDC manages the national-level influenza clinical sentinel surveillance, laboratory respiratory virus sentinel surveillance, and hospital-based surveillance systems, with weekly reports $[8,10]$. These surveillance systems are independent of each other. Patients registered in the surveillance systems do not belong to a specific cohort but are registered when a patient voluntarily visits individual medical institutions where the surveillance is being conducted. For the status and analysis of COVID-19 data in Korea, a separate daily report from KCDC was used [11].

\section{Influenza clinical sentinel surveillance}

Influenza clinical surveillance in Korea is conducted through 200 pre-selected outpatient clinics nationwide. The total number of patients visiting the clinics and the number of patients with influenza-like illness (ILI), stratified by age group, are reported as the number of ILI patients per 1,000 patients. ILI symptoms include cough or sore throat with a sudden onset of fever $>38^{\circ} \mathrm{C}$ [8]. Here, we collected the ILI data reported over 4 years and compared the yearly trends, to identify the prevalence and patterns of influenza.

\section{Laboratory respiratory virus sentinel surveillance}

The Korea Influenza and Respiratory Virus Surveillance System (KINRESS) identifies major respiratory viral causative agents in the respiratory samples (throat or nasopharyngeal swabs) of patients with acute respiratory illnesses (ARIs), including influenza. The KINRESS identifies the weekly pathogen-based epidemic patterns, monitors the appearance of new viruses, and analyzes antiviral resistance $[12,13]$. Respiratory samples were collected from patients who consented to testing at 52 pre-selected medical institutions where the ILI-monitoring surveillance systems described above were conducted. Inclusion criteria were patients with ILI or ARIs who visited the hospital, with typical symptoms occurring within 3 days of onset [9]. The collected samples were transported to 17 Institutes of Health and Environment across the country. Multiplex real-time polymerase chain reaction (PCR)/reverse-transcription-PCR was performed to identify the respiratory virus genes for all eight types and 15 subtypes [14]. Targeted viruses included human adenovirus (HAdV), human parainfluenza virus (HPIV types 1, 2, and 3), human respiratory syncytial virus (HRSV types $A$ and $B$ ), influenza virus (IFV A/H1N1(pdmo9), A/H3N2, and B), human coronavirus (HCoV 229E, OC43, and NL63), human rhinovirus (HRV), human bocavirus (HBoV), and human metap- 
neumovirus (HMPV). The remaining respiratory samples after this initial screening test were sent to the central KCDC for retesting for unidentified specimens. We analyzed the KINRESS data from January 2016 to April 2020 , to identify changes in the patterns of the seasonal respiratory virus epidemic. In this study, seasonal influenza epidemic duration was defined based on laboratory results. The influenza epidemic period was defined from the week when the positive influenza ratio (the number of influenza-positive/the number of total tests) increased by $\geq 5 \%$ to the week before it fell to $<5 \%$. The exacerbation period was defined from the beginning of the epidemic to the week when the positive influenza ratio was the highest, while the relief period was defined from the epidemic peak to the epidemic end. In Korea, the influenza epidemic occurred with both influenza A and influenza B (2017-2018 and 2019-2020) simultaneously, or influenza B epidemic occurred only after the end of the influenza A epidemic (2016-2017 and 20182019). The latter epidemic seasons were evaluated based on the first initial presentation of influenza $A$ in the epidemic [15].

\section{Hospital-based surveillance system}

Selected hospitals by the KCDC monitor the hospitalization due to respiratory virus infections. Nationwide, 206 hospital-level medical institutions register patients with confirmed viral pathogens who exhibit clinical symptoms consistent with ARIs and patients who are infected with one of the eight respiratory viruses (HAdV, HPIV, HRSV, IFV, HCoV, HRV, HBoV, and HMPV) or two bacteria (Mycoplasma pneumoniae and Chlamydophila pneumoniae) $[9,10]$. This hospital-based surveillance system did not include COVID-19 cases.

\section{Cross-sectional survey for individual preventive measures}

We conducted a cross-sectional online survey to compare the general public's use of masks and personal hygiene status during the COVID-19 pandemic, independently of the ongoing surveillance systems in Korea. For the survey, the pre-COVID-19 pandemic period in Korea was defined from December 1, 2019, to January 31, 2020, and the COVID-19 pandemic period from February 1, 2020, to March 31, 2020. From January 27, 2020, when the outbreak spread nationwide, the national in- fectious disease alert level went from 'caution' to 'alert.' A third-generation transmission case occurred on January 31,2020 , and since then, the use of masks by the general public surged, according to media reports [16]. The survey was used to collect data on the age, sex, healthcare worker occupation status, perception on wearing masks, and reasons for using masks. It also compared the use of masks during outings and in the work setting, on public transportation, and in indoor spaces with the use in other settings, such as supermarkets and bus terminals, before and after the pandemic. The survey also inquired about the type of masks most frequently used before and after the pandemic. Furthermore, the coughing etiquette and hand-washing practice were compared. An online survey platform was used, and survey participants were not restricted, because the survey was open to everyone. To compare the rates of use of preventive measures by individuals before and after the COVID-19 pandemic, the following Likert-type responses were included: "Never," "Seldom," "Generally," or "Always." Depending on the level of use of preventive measures, the question was scored from 1 for "Never" to 4 for "Always." Additional information on the survey is available in the Appendix 1.

\section{Estimating the compliance with the physical dis- tancing measure}

As the number of COVID-19 cases began to increase sharply, on February 29, 2020, the health authorities recommended voluntary social distancing. Except for confirmed cases and their close contacts, compulsory lockdowns and measures were not strictly enforced. To evaluate the compliance with the physical distancing measure, the weekly number of passengers in the Seoul Metropolitan Subway during the outbreak was compared to the numbers from the previous 2 years, using data from 275 subway stations reported by the Seoul Metro [17].

\section{Statistical analysis}

For the surveillance data, the Student's $t$ test was used to compare the yearly positive ratio, while the Kruskal Wallis test and the Games-Howell test were used to analyze the pattern, based on the respiratory virus surveillance data during influenza epidemics and during post-influenza weeks. Mask use and personal hygiene 
practice before and after the COVID-19 pandemic were compared by paired $t$ test. To analyze the correlation of compliance among preventive measures, Pearson's correlation coefficients were calculated. All analyses were performed using IBM SPSS Statistics for Windows version 26.o (IBM Corp., Armonk, NY, USA).

\section{Ethics}

The Hallym University Sacred Heart Hospital Institutional Review Board was consulted, and this proposal did not require ethics approval (HALLYM 2020-03-032o01). The reasons for this decision are as follows: First, the data used for surveillance analysis were disclosed to the public without personally identifiable information by the KCDC, and this analysis purpose is not evaluating a specific test or treatment. Second, although the online survey was a human study, the subject was not limited to a specific person or group, and personal information were not collected and recorded. The need to obtain written informed consent for participation in the online survey was waived owing to the rapid emergence of this infectious disease and the survey was completed anonymously.

\section{RESULTS}

Fig. 1 shows the summary of the COVID-19 pandemic in Korea. As of April 24, 2020, there were 10,708 patients with confirmed COVID-19, with 59.6\% women and an average age of 44 years. The overall mortality rate was $2.2 \%$ [11]. Additional details are available in the Appen$\operatorname{dix} 2[18-21]$.

\section{Individual-level preventive measures before and after the COVID-19 pandemic}

Overall, 604 subjects responded to the survey, including $60.3 \%$ female and $6.5 \%$ healthcare providers. The response of "always" or "generally" use masks during regular outings or at work increased from 12.3\% (74/604) before the pandemic to $94.9 \%$ (573/604) during the pandemic (Table 1, Fig. 2, Supplementary Table 1, and Supplementary Fig. 1) [22]. The response to whether they "always" or "generally" use masks in public transportation and public indoor spaces with other people also showed a significant increase. After the COVID-19 pandemic, females had a higher rate of use of masks and washed hands more frequently than males (Supplementary Tables 2 and 3). Both before and during the COVID-19 pandemic, the mask-wearing rate and hand-washing frequency, and coughing etiquette showed significant correlations (Supplementary Tables 4 and 5).

\section{Compliance with the physical distancing measure}

In 2019, 1,799,719,433 passengers used the Seoul Metro. Further, on average, 34 million passengers used the Seoul Metro per week. This remained consistent throughout the year, except for weeks that included > three national holidays. After the Korean health authorities recommended voluntary social distancing in week 9 of 2020 , the number of passengers decreased by $38 \%$ compared to those of previous years, as shown in Fig. ${ }_{3} \mathrm{C}(21,810,500 ; 35,169,961$; and 35,085,751 passengers per week for 2020, 2019, and 2018, respectively; $p<0.001$ ).

\section{Changes in influenza clinical sentinel surveillance data}

Fig. 3A shows the results from the influenza clinical surveillance in the past 4 years. The influenza epidemic pattern in 2019-2020, compared to those in 2016-2017, 2017-2018, and 2018-2019 (for influenza A), showed an overall flat trend, and the epidemic declined before reaching the peak. The peak ILI rate (cases per 1,000 patients) in 2019-2020 of 49.8 was lower than that of 2016-2017 (86.2), 2017-2018 (72.1), and 2018-2019 (73.3). The average number of ILI patients over the 3 weeks (the week of the highest peak, and 1 week before and after the peak), which was 48.9 in 2019-2020, was significantly lower $(p=0.05)$ than those in previous years $(2016-2017$, 70.5; 2017-2018, 71.0; and 2018-2019, 66.1). Furthermore, the slope of the new numbers of ILI patients steeply declined from the fourth to the 6th week of 2020.

\section{Changes in laboratory respiratory virus surveillance data}

Table 2 shows the pattern of influenza epidemics, based on the laboratory-confirmed positive testing rates of influenza from surveillance results, across the influenza seasons. In previous seasons, the exacerbation period was shorter than the relief period when influenza spread rapidly in the community and then slowly recovered. Conversely, in the 2019 to 2020 season, the exacerbation 


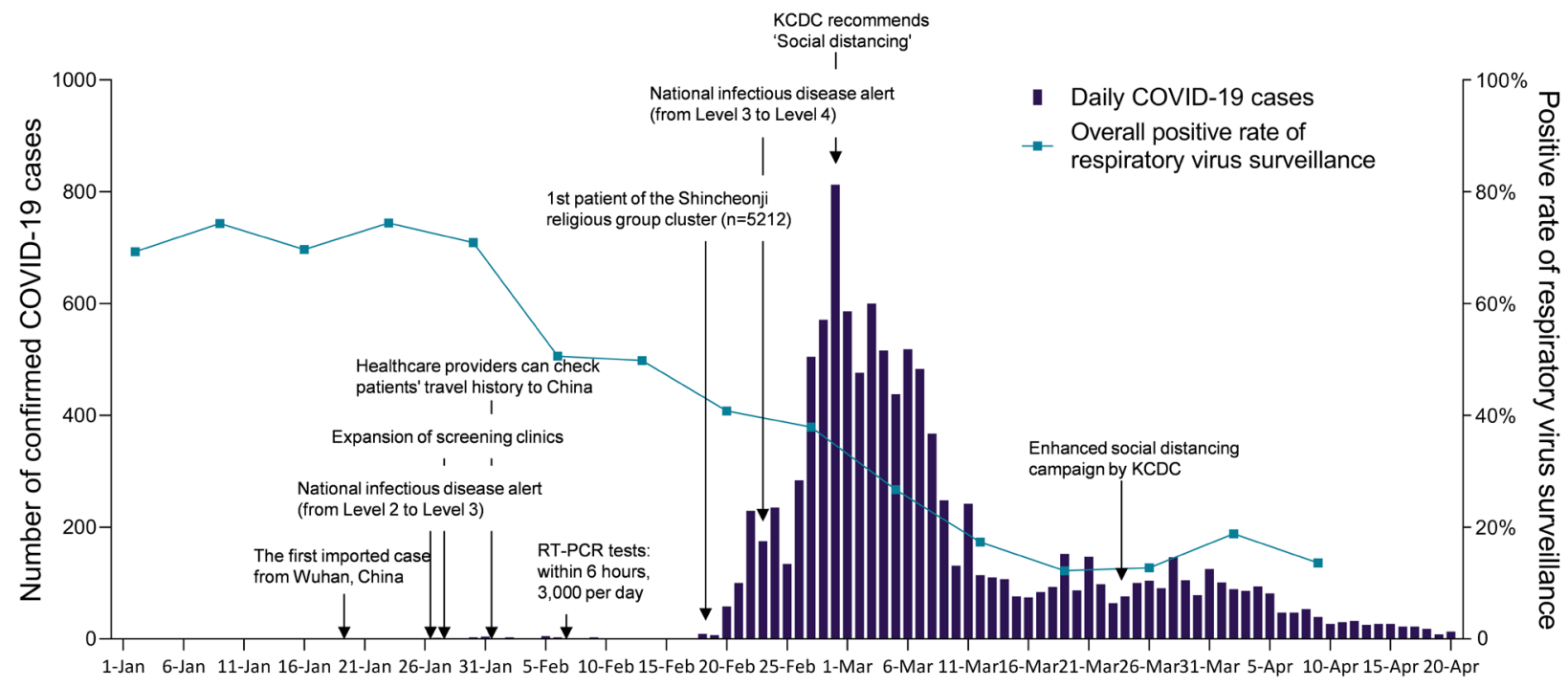

Community-based Measures

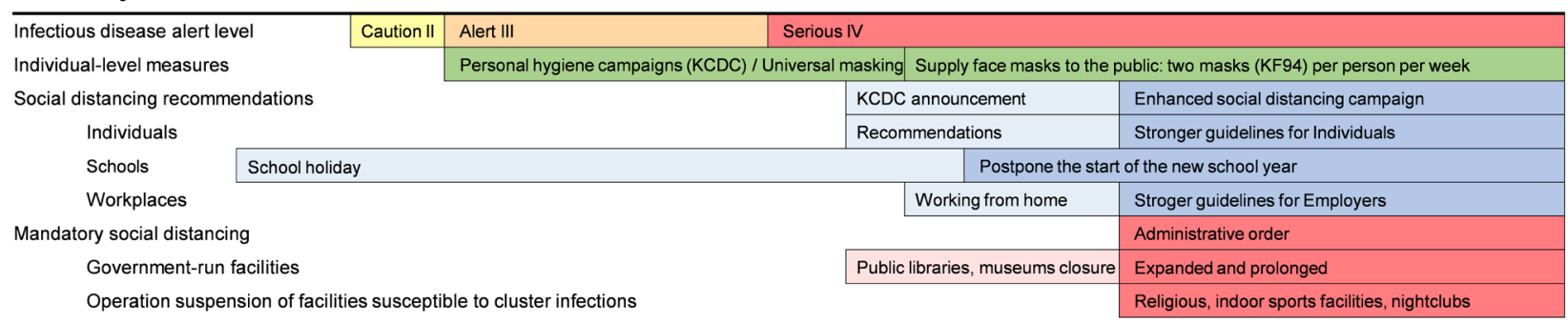

Immigration-related Measures

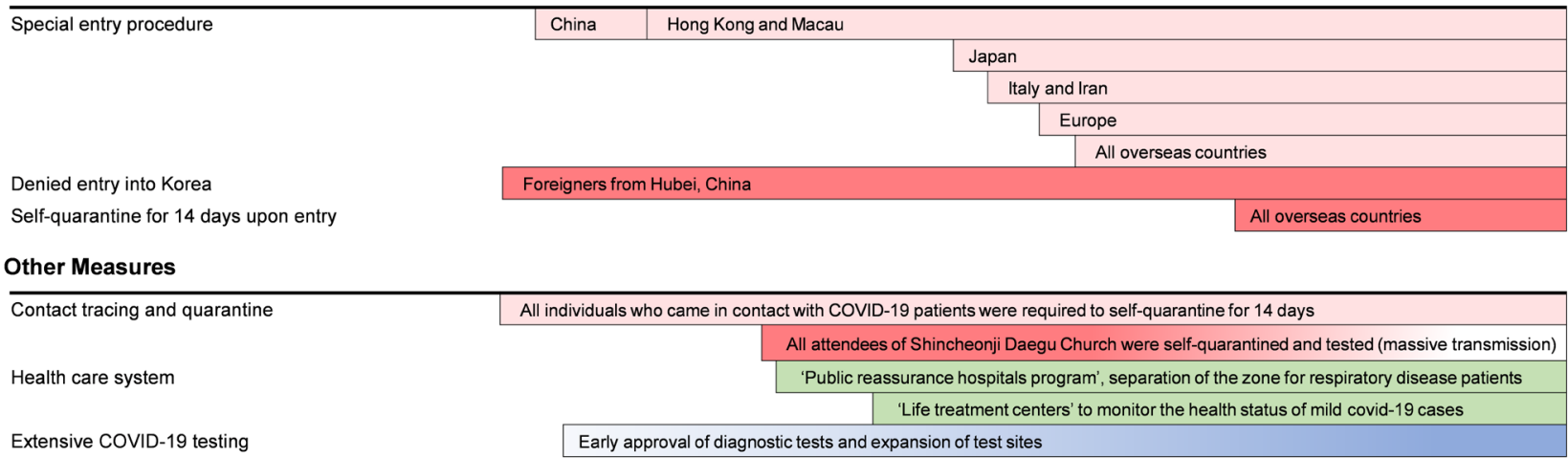

Figure 1. Daily numbers of coronavirus disease 2019 (COVID-19) cases and respiratory virus surveillance in South Korea. The dark blue bars indicate the daily-confirmed COVID-19 cases. The light blue line indicates the weekly positive rate of laboratory respiratory virus surveillance (all eight types, including influenza) in the 2019 to 2020 influenza epidemic and post-influenza period. KCDC, Korean Centers for Disease Control and Prevention; RT-PCR, reverse transcription-polymerase chain reaction.

period lasted for 13 weeks, with a 3-week relief period, and then, the epidemic quickly ended. When comparing the weekly average number of patient decline, to compare the alleviation rates of the influenza epidemic, yearly, the number of patients declined approximately 1.8 to 2.5 times faster than in the previous year. The quick end to the flu epidemic coincided with the beginning of the COVID-19 pandemic, a period of national interest for personal protection use, including the widespread use of masks (Fig. $3 \mathrm{C}$ ).

Table 3 shows the comparison of yearly laboratory surveillance results for all respiratory viruses. In the respira- 
Table 1. Perception towards the use of masks and individual-level preventive measures before and after the COVID-19 pandemic, obtained from the online survey in South Korea

\begin{tabular}{|c|c|c|c|}
\hline \multirow[b]{2}{*}{ Question } & \multicolumn{2}{|c|}{ Response frequency $(\mathrm{n}=604)$} & \multirow[b]{2}{*}{$p$ value $^{b}$} \\
\hline & $\begin{array}{l}\text { Before COVID-19 } \\
2019.12-2020.1^{\mathrm{a}}\end{array}$ & $\begin{array}{l}\text { After COVID-19 } \\
2020.2-2020.3^{a}\end{array}$ & \\
\hline \multicolumn{4}{|l|}{ Characteristics } \\
\hline Female sex & \multicolumn{2}{|c|}{$364(60.3)$} & \\
\hline Health-care worker & \multicolumn{2}{|c|}{$39(6.5)$} & \\
\hline \multicolumn{4}{|l|}{ Age group, yr } \\
\hline $18-29$ & \multicolumn{2}{|c|}{$77(12.7)$} & \\
\hline $30-39$ & \multicolumn{2}{|c|}{$153(25 \cdot 3)$} & \\
\hline $40-49$ & \multicolumn{2}{|c|}{$142(23 \cdot 5)$} & \\
\hline $50-59$ & \multicolumn{2}{|c|}{$168(27.8)$} & \\
\hline $60-69$ & \multicolumn{2}{|c|}{$52(8.6)$} & \\
\hline$\geq 70$ & \multicolumn{2}{|c|}{$12(2.0)$} & \\
\hline \multicolumn{4}{|l|}{ Perception of the use of masks } \\
\hline $\begin{array}{l}\text { It is necessary to wear a mask regularly to protect myself } \\
\text { against the virus (yes) }\end{array}$ & \multicolumn{2}{|c|}{$584(96.7)$} & \\
\hline People wearing masks may be patients (yes) & \multicolumn{2}{|c|}{$17(2.8)$} & \\
\hline \multicolumn{4}{|l|}{ The reasons for using masks } \\
\hline For personal protection from the infection & \multicolumn{2}{|c|}{$514(85.1)$} & \\
\hline To prevent transmission of infection to people around them & \multicolumn{2}{|c|}{$401(66.4)$} & \\
\hline $\begin{array}{l}\text { Because everyone else wears them and they did not want } \\
\text { to be singled out for not wearing them }\end{array}$ & \multicolumn{2}{|c|}{$121(20.0)$} & \\
\hline It is necessary in the work setting & \multicolumn{2}{|c|}{$90(14.9)$} & \\
\hline \multicolumn{4}{|l|}{ Preventive measures ${ }^{\mathrm{c}}$} \\
\hline Wearing a mask during regular outings or at work & $1.60 \pm 0.76$ & $3.54 \pm 0.61$ & $<0.001$ \\
\hline Wearing a mask in public transportation $(n=598)^{d}$ & $1.52 \pm 0.78$ & $3.80 \pm 0.48$ & $<0.001$ \\
\hline Wearing a mask in public indoor spaces with other people & $1.51 \pm 0.75$ & $3.75 \pm 0.52$ & $<0.001$ \\
\hline Adhering to correct cough etiquette $\mathrm{e}^{\mathrm{e}}$ & $2.63 \pm 0.90$ & $3.58 \pm 0.59$ & $<0.001$ \\
\hline Adhering to correct hand-washing ${ }^{e}$ & $2.69 \pm 0.80$ & $3.53 \pm 0.60$ & $<0.001$ \\
\hline Score for correct hand-washing practice ${ }^{f}$ & $2.31 \pm 0.68$ & $3.04 \pm 0.75$ & $<0.001$ \\
\hline
\end{tabular}

Values are presented as number (\%) or mean \pm standard deviation.

COVID-19, coronavirus disease 2019.

${ }^{a}$ For the survey, the cut-off day for the COVID-19 pandemic was defined as January 31, 2020. On January 27, the national infectious disease alert level went from 'caution' to 'alert.'

${ }^{\mathrm{b}}$ The mask use and personal hygiene practice before and after the COVID-19 pandemic were compared by paired $t$ test.

"Likert scale responses: "Never," "Seldom," "Generally," and "Always." Depending on the level of use, the question was scored from 1 for "Never" to 4 for "Always."

${ }^{\mathrm{d}}$ Data were missing for six patients. Except for this item, all respondents had to complete the mandatory answers when proceeding with the online surveys and submit the final responses. The responses of the respondents who stopped in the middle of the questionnaire could not be collected.

${ }^{\mathrm{e}}$ Cover the mouth and nose with tissue or elbow when coughing or sneezing. Wash the hands with running water and soap or sanitizer for at least 30 seconds, using the recommended six steps by Korean Centers for Disease Control and Prevention.

${ }^{\mathrm{f}}$ Scores for proper hand washing practice: 1 point (not done); 2 points (1-5 times); 3 points (6-10 times); 4 points (more than 10 times). 

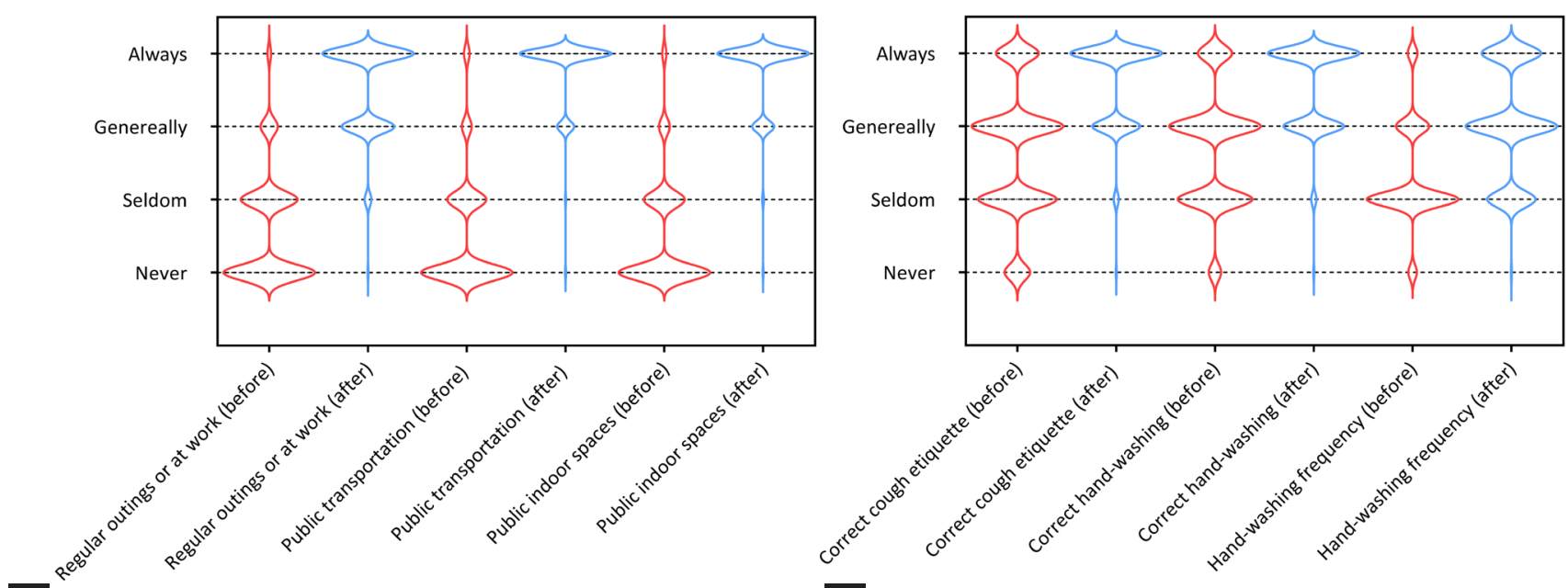

A

B

Figure 2. Online survey results for the use of individual-level preventive measures in the pre- and coronavirus disease 2019 (COVID-19) pandemic-periods. (A) Violin plots of universal masks in those at risk of social contact. (B) Violin plots of the appropriateness of coughing etiquette and hand washing, and the daily number of hand-washings. For this online survey, preCOVID-19 pandemic period in Korea was defined from December 1, 2019 to January 31, 2020 while the COVID-19 pandemic period from February 1, 2020 to March 31, 2020.

Table 2. Analysis of the annual influenza incidence rates based on laboratory-confirmed test data

\begin{tabular}{|c|c|c|c|c|c|}
\hline \multirow{2}{*}{ Variable } & \multicolumn{5}{|c|}{ Years of influenza seasons } \\
\hline & $2016-2017$ & $2017-2018$ & $2018-2019$ & $2019-2020$ & $p$ value \\
\hline Duration of epidemics, $\mathrm{wk}^{\mathrm{a}}$ & $\begin{array}{c}14 \\
\text { (influenza A) }\end{array}$ & 19 & $\begin{array}{c}14 \\
(\text { influenza A) }\end{array}$ & 16 & - \\
\hline \multicolumn{6}{|l|}{ Duration of epidemic phases, wk $^{\mathrm{b}}$} \\
\hline Exacerbation phase & 4 & 6 & 6 & 13 & $0.002^{c}$ \\
\hline Relief phase & 10 & 13 & 8 & 3 & \\
\hline \multicolumn{6}{|l|}{ Alleviation rates of seasonal epidemics } \\
\hline Mean positive reduction rate per week, \% & -4.85 & -4.81 & -4.92 & -9.20 & $0.995^{\mathrm{d}}$ \\
\hline Mean reduction in no. of patients per week, \% & $-13 \cdot 5$ & $-13 \cdot 5$ & -18.3 & $-34 \cdot 0$ & $0.452^{\mathrm{d}}$ \\
\hline
\end{tabular}

${ }^{a}$ The period of the epidemic was between when the test positivity of influenza increased by $\geq 5 \%$ to the week before it fell to $<5 \%$. ${ }^{b}$ The exacerbation period was from the beginning of the epidemic to the week when the test positivity of influenza was the highest, while the relief period was the period from the peak to the end of the epidemic.

'Statistical significance was tested by the linear-by-linear association.

${ }^{\mathrm{d}}$ Statistical significance was tested by Kruskal-Wallis test.

tory samples collected throughout the year, the average overall virus-positive rate was $56.6 \%$ to $63.0 \%$. The yearly positive rates of the respiratory virus during the 8-week post-influenza period after the end of the epidemic were compared. During the post-influenza periods, the positive rates remained high (2016-2017, 47.7\%; 2017-2018, 69.9\%; 2018-2019, 67.6\%), and it was confirmed that HRV, HPIV, or HMPV mainly replaced influenza and become prevalent in the community during these periods. However, the overall respiratory virus-positive rates during the 8-week post-influenza period in 2019 to 2020 averaged $26.5 \%$, keeping the positive ratio low. The overall respiratory viral infection collectively decreased (Fig. 3B). Prior to implementing the social distancing measure, the seasonal respiratory virus was controlled following strong adherence to personal preventive 
Table 3. Positive rates of respiratory virus infection confirmed during laboratory surveillance, stratified by year and post-influenza epidemic period (8 weeks)

\begin{tabular}{|c|c|c|c|c|c|c|c|c|c|c|}
\hline \multirow{2}{*}{$\begin{array}{l}\text { Year or } \\
\text { influenza } \\
\text { season }\end{array}$} & \multirow[b]{2}{*}{ Duration, wk } & \multirow[b]{2}{*}{ Total } & \multirow{2}{*}{$\begin{array}{c}\text { Total } \\
\text { positive } \\
\text { rate, \% }\end{array}$} & \multirow{2}{*}{$p$ value ${ }^{b}$} & \multicolumn{6}{|c|}{ Positive rate for individual respiratory virus ${ }^{\mathrm{a}}$} \\
\hline & & & & & $\mathrm{HCoV}, \%$ & HRV, \% & HPIV, \% & HMPV, \% & HAdV, \% & IFV, \% \\
\hline 2016 & 53 & 11,111 & 59.0 & - & $5 \cdot 5$ & 15.0 & 6.0 & 4.1 & 6.3 & $15 \cdot 9$ \\
\hline 2017 & 52 & 11,915 & 56.6 & - & $4 \cdot 4$ & $19 \cdot 4$ & 6.3 & $5 \cdot 3$ & $3 \cdot 7$ & 10.9 \\
\hline 2018 & 52 & 11,966 & 63.0 & - & $5 \cdot 7$ & 16.3 & 6.1 & $4 \cdot 9$ & 6.8 & 17.0 \\
\hline 2019 & 52 & 12,151 & 60.2 & - & 2.9 & 17.2 & 6.4 & 5.0 & 8.0 & 14.0 \\
\hline $2016-17$ & Post-epidemic, $8^{c}$ & 1,702 & $47 \cdot 7$ & 0.002 & 2.2 & 18.0 & $14 \cdot 5$ & 1.3 & $4 \cdot 9$ & 1.7 \\
\hline $2017-18$ & Post-epidemic, $8^{c}$ & 1,868 & 69.9 & $<0.001$ & 2.1 & 25.1 & 10.8 & $17 \cdot 3$ & $5 \cdot 4$ & 2.9 \\
\hline $2018-19$ & Post-epidemic, $8^{c}$ & 1,563 & 67.6 & $<0.001$ & 1.2 & 20.2 & 18.2 & 6.9 & $9 \cdot 3$ & 1.3 \\
\hline $2019-20$ & Post-epidemic, $8^{c}$ & 845 & 26.5 & NA & $4 \cdot 3$ & 6.4 & 0.2 & 2.6 & 6.6 & 1.3 \\
\hline
\end{tabular}

HCoV, human coronavirus; HRV, human rhinovirus; HPIV, human parainfluenza virus types; HMPV, human metapneumovirus; HAdV, human adenovirus; IFV, influenza virus; NA, not available.

${ }^{a} \mathrm{HPIV}$ (human parainfluenza virus types 1, 2, and 3), HRSV (human respiratory syncytial virus types A and B), IFV (influenza $\mathrm{A} / \mathrm{H}_{1} \mathrm{~N} 1(\mathrm{pdmo9})$ and $\left.\mathrm{A} / \mathrm{H}_{3} \mathrm{~N}_{2} \mathrm{~B}\right), \mathrm{HCoV}$ (human coronavirus 229 $\mathrm{E}, \mathrm{OC}_{43}$, and $\mathrm{NL}_{3}$ ).

${ }^{\mathrm{b}}$ Games-Howell test was applied to compare the positive rate of the total respiratory virus infection in 2019 to 2020 with the other years' 8th-week post-influenza periods.

${ }^{\mathrm{c}}$ Post-seasonal influenza epidemic period (8 weeks): 2016-2017 season (2017, 21st to 28th week); 2017-2018 season (2018, 15th to 22nd week); 2018-2019 season (2019, 23rd to 30th week); and 2019-2020 season (2020, 8th to 15th week).

measures. After voluntary social distancing was implemented, the positivity rate continued to decrease and remained low (Fig. 3C). Supplementary Fig. 2 shows the weekly changes in the number of hospitalizations due to respiratory virus infection, using hospital-based surveillance system data. It showed a decrease in the number of patients diagnosed with respiratory viral infections of all types, confirmed by the laboratory data.

\section{DISCUSSION}

This study showed that the use of masks and compliance with personal hygiene practices by Koreans in their daily lives increased following the COVID-19 pandemic. After personal preventive measures were implanted in Korea, the transmission of seasonal respiratory viruses, including influenza, dramatically decreased. These results indirectly suggest that the increased compliance with personal preventive measures suppressed the overall transmission of respiratory viruses.

Respiratory viral diseases, such as infections caused by influenza and rhinovirus, spread widely within local communities [23]. However, to prevent this community spread, neither do we wear advanced protective equipment nor trace contacts or isolate infected individuals. This is because most respiratory viral infections produce mild symptoms, and it is not practical to implement such measures in the general community. Conversely, the effectiveness of wearing masks and following hand hygiene measures in a healthcare setting or a small cohort (dormitory, household, etc.) to prevent the spread of respiratory viruses has been proven in previous studies [24]. The effectiveness of wearing masks can be classified in many ways. When masks are used by people with respiratory infections, it helps reduce the spread of infection by reducing droplet discharge [25]. When a healthcare worker uses masks, droplet or aerosol-based infections from infected patients can be prevented [24]. Despite some inconsistent results, the majority of studies demonstrated the effectiveness of masks when used in specific adherent groups [26-30]. A randomized clinical trial (RCT) comparing three groups: one that uses surgical masks, another that uses P2 (N95) masks, and a control group, in 143 households with children diagnosed and confirmed with ARIs showed that masks 

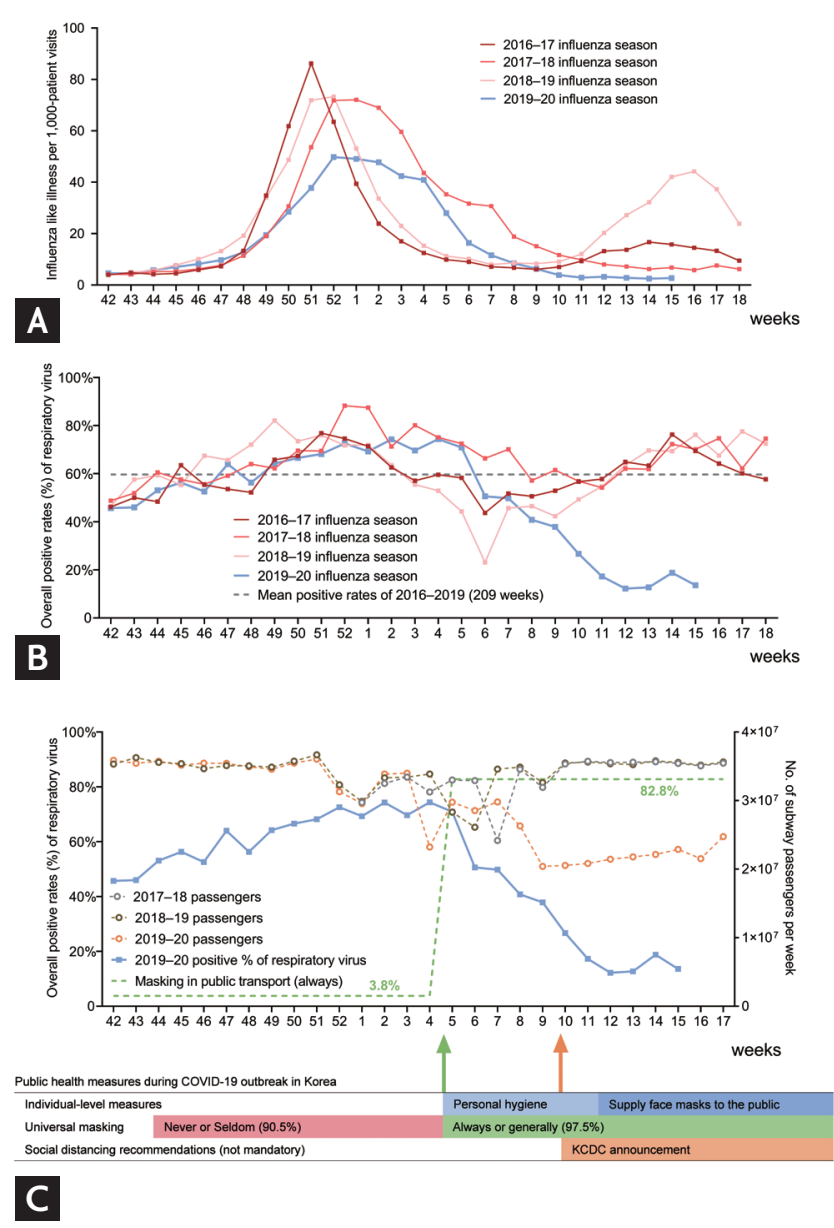

Figure 3. (A) Influenza-like illness analysis by year. (B) Annual positivity rates of overall respiratory virus infection confirmed during laboratory surveillance during the influenza epidemic and post-influenza periods, weekly, from 2016 to 2020 . (C) The timeline of the public health measures implemented and adherence to them, during the coronavirus disease 2019 (COVID-19) pandemic in South Korea. The green dotted line indicates the rates of wearing of face masks in public transportation. The orange dotted line indicates the weekly number of passengers in the Seoul Metropolitan subway as a social distancing indicator. A decrease in the number of passengers was observed over 3 years, during the weeks with the three national holidays (Lunar New Year holidays: 4th, 6th, and 7th weeks in 2020, 2019, and 2018, respectively). The blue line indicates the respiratory virus positivity rate as an effectiveness indicator. KCDC, Korean Centers for Disease Control and Prevention.

were not effective in preventing infection. However, the adherent users with frequent mask usage were less than $50 \%$ in both mask groups. Interestingly, these users showed a reduced risk of infection in the family by about 70\% [30]. An RCT comparing controls, face mask alone, and face mask with hand hygiene among young adults in college dormitories reported that after 4 to 5 weeks, ILI risk was reduced by about $35 \%$ in both intervention groups compared to that in controls [27]. The aforementioned interventions were also performed in 259 households with index cases of confirmed influenza. The intervention groups showed a low secondary infection rate, with a statistically significant preventive effect, in 154 households where the intervention began within 3 days of index case symptom onset [28]. Thus, when using masks to prevent a secondary respiratory viral infection, the rate of compliance with mask use and their early use during the infectious stage is important. These results are similar to those in the real-world setting in Korea. In the early stages of the COVID-19 pandemic, the widespread use of masks began. In this context, Lee et al. [31] reported similar results, with an early end to the 2019 to 2020 influenza season in Korea.

The use of masks is also effective in reducing microbial colonization in the mucosal layer of the upper respiratory tract [32]. This indirectly suggests that wearing masks might reduce the potential spread of infection from asymptomatic patients. Considering the presence of asymptomatic infectious agents before symptom onset in the transmission of respiratory infections, including COVID-19, this is an important finding [33,34]. Another effect of masks is the role of social behavioral modification. Widespread mask-wearing allows individuals to observe better personal hygiene, such as not touching the face, and to provide a visual reminder to maintain social distances. In our study, the use of masks was positively correlated with hand washing and coughing etiquette.

Our research has several limitations. First, the number of visits to the medical institutions may have been underdetermined because patients with respiratory viral infections may have visited the medical institutions less frequently during the COVID-19 pandemic. However, the COVID-19 pandemic in Korea was not so severe that it limited the use of medical resources, except in Daegu City. During the pandemic, the institutions of surveillance, indications for inclusion, and testing process were not changed. The interpretation of the results of surveillance by test positivity was appropriate because the surveillance was not performed in a cohort group but active sentinel surveillance was conducted for 
patients who visited the institutions with symptoms. These test positivity data reflect the seasonal patterns of the individual viruses, including influenza, well, which has been affirmed in previous studies [31,35]. Moreover, the decrease in the number of hospitalized patients who were confirmed with respiratory viral pneumonia due to severe symptoms and the absence of the 2020 to 2021 seasonal influenza epidemic are clear additional evidence. Second, this study was not a case-control study, thus it was not possible to explain the differences in infection prevention by the types of masks used. Because masks are difficult to get, some people disinfected or reused their masks or worn cotton masks. In the worst pandemic situations, the lack of masks is a major problem. As with the recently revised Centers for Disease Control and Prevention recommendations, wearing a cloth mask may be a temporary measure. Third, the correlation between the number of subway riders and compliance with social distancing measures was not well validated. We used this as an alternative because there is no validation index to evaluate the compliance with social distancing objectively and numerically [36,37]. The advantage of subway passenger data is that because the subway is a means of short-distance transportation and these data represent information on essential daily movements, such as commuting, shopping, and attending school. Moreover, these are important physical distancing interventions. Fourth, it is impossible to determine which preventive measures were most effective. In Korea, the seasonal respiratory virus was controlled prior to implementing the social distancing campaign. Compliance with personal preventive measures was much higher than compliance with social distancing measures. The combined measures of broad and strong mandatory social distancing may effectively control the COVID-19 pandemic. The effect of these measures has already been demonstrated by the Chinese through their experience and through epidemic simulation modeling $[38,39]$. However, not all members of society continue to maintain social distance, especially those with low incomes or who are unemployed. Even if COVID-19 continues, people have no choice but to work, shop for food, and use public transportation. The universal use of masks during inevitable social meetings may be a simple and inexpensive way to prevent the spread of hidden infections from unidentified symptomatic and asymptomatic patients.

In conclusion, the increase in the use of individual-level preventive measures on a national level helped control the seasonal respiratory virus transmission, which does not generally necessitate additional quarantine, such as isolation or contact screening. This indirectly suggests that the increased use of personal protective measures in public areas may decrease the rate of respiratory virus transmission. Further studies are needed to compare the effectiveness of each public health measure by integrating data of implemented measures against the COVID-19 pandemic from various countries.

\section{KEY MESSAGE}

1. Effectiveness of public health prevention measures in real-world settings is unknown.

2. COVID-19 individual preventive measures were strictly adhered to in South Korea.

3. Seasonal respiratory viruses were controlled nationally.

4. Preventive measures may provide 'herd defense' against respiratory viruses.

\section{Conflict of interest}

No potential conflict of interest relevant to this article was reported.

\section{Acknowledgments}

The author would like to thank Kyung-hee Kim, M.D. for constructively criticizing the manuscript. We also thank the survey participants.

\section{REFERENCES}

1. Li Q, Guan X, Wu P, et al. Early transmission dynamics in Wuhan, China, of novel coronavirus-infected pneumonia. N Engl J Med 2020;382:1199-1207.

2. Korea Disease Control and Prevention Agency. How to wear a mask correctly to prevent infection 2020 [Internet]. Cheongju (KR): Korea Disease Control and Prevention Agency, 2020 [cited 2021 July 13]. Available from: http:// ncov.mohw.go.kr/infoBoardView.do?brdId=3\&brd- 
Gubun $=32 \&$ dataGubun $=\&$ ncvContSeq $=71 \& \operatorname{contSe}-$ $\mathrm{q}=71 \&$ board_id=\&gubun=.

3. Feng S, Shen C, Xia N, Song W, Fan M, Cowling BJ. Rational use of face masks in the COVID-19 pandemic. Lancet Respir Med 2020;8:434-436.

4. Wong T. Coronavirus: why some countries wear face masks and others don't [Internet]. London (UK): BBC, 2020 [cited 2021 July 13]. Available from: https://www.bbc. com/news/world-52015486.

5. Greenhalgh T, Schmid MB, Czypionka T, Bassler D, Gruer L. Face masks for the public during the covid-19 crisis. BMJ 2020;369:m1435.

6. Cho SY, Kang JM, Ha YE, et al. MERS-CoV outbreak following a single patient exposure in an emergency room in South Korea: an epidemiological outbreak study. Lancet 2016;388:994-1001.

7. Cho ME, Kim MJ. Residents' perceptions of and response behaviors to particulate matter: a case study in Seoul, Korea. Appl Sci 2019;9:3660.

8. Choi WS. The national influenza surveillance system of Korea. Infect Chemother 2019;51:98-106.

9. Korea Disease Control and Prevention Agency. Respiratory disease management guidelines 2020 [Internet]. Cheongju (KR): Korea Disease Control and Prevention Agency, 2020 [cited 2021 July 13]. Available from: https://is.cdc.go.kr/upload_comm/syview/doc.htm1?fn=15813942053780o.pdf\&rs=/upload_comm/docu/oo19/.

10. Korea Disease Control and Prevention Agency. 2019-2020 Influenza management guidelines [Internet]. Cheongju (KR): Korea Disease Control and Prevention Agency, 2019 [cited 2021 July 13]. Available from: https://is.cdc.go.kr/ upload_comm/syview/doc.html?fn=1573114201586oo.pdf\&rs=/upload_comm/docu/oorg/.

11. Korea Disease Control and Prevention Agency. Updates on COVID-19 in Republic of Korea [Internet]. Cheongju (KR): Korea Disease Control and Prevention Agency, 2020 [cited 2021 July 13]. Available from: http://ncov.mohw. go.kr/en/tcmBoardList.do?brdId=12\&brdGubun=125\&dataGubun=\&ncvContSeq=\&contSeq=\&board_id=\&gubun=.

12. Korea Disease Control and Prevention Agency. Weekly Sentinel Surveillance Report [Internet]. Cheongju (KR): Korea Disease Control and Prevention Agency, 2020 [cited 2021 July 13]. Available from: http://www.cdc.go.kr/npt/biz/ npp/portal/nppPblctDtaView.do?pblctDtaSeAt=2\&pblct$\mathrm{DtaSn}=2092$.
13. Korea Centers for Disease Control and Prevention, Center for Laboratory Control of Infectious Diseases, Division of Viral Diseases. Pathogens \& vector surveillance weekly report [Internet]. Cheongju (KR): Korea Disease Control and Prevention Agency, 2020 [cited 2021 July 13]. Available from: http://www.cdc.go.kr/npt/biz/npp/portal/ nppPblctDtaMain.do.

14. Kim JM, Jung HD, Cheong HM, et al. Nation-wide surveillance of human acute respiratory virus infections between 2013 and 2015 in Korea. J Med Virol 2018;90:11771183.

15. Park K, Park S, Kwon D, et al. Influenza sentinel surveillance report in the Republic of Korea, 2018-2019 [Internet]. Cheongju (KR): Korea Disease Control and Prevention Agency, 2019 [cited 2021 July 13]. https://is.cdc.go.kr/ upload_comm/syview/doc.html?fn=157554200276400.pdf\&rs=/upload_comm/docu/oo34/.

16. Lee E, Lee KP, Lee MJ. Korean government works to counter mask, hygiene product shortage 2020 [Internet]. Seoul (KR): Korea JoongAng Daily, 2020 [cited 2021 July 13]. Available from: https://koreajoongangdaily.joins.com/ news/article/article.aspx?aid=3073396.

17. Seoul Metro. Status of subway operation [Internet]. Seoul (KR): Seoul Metro, 2019 [cited 2021 July 13]. Available from: http://www.seoulmetro.co.kr/kr/board.do?menuIdx=548.

18. Korea Disease Control and Prevention Agency. Weekly report on the COVID-19 situation in the Republic of Korea (As of April 18, 2020) [Internet]. Cheongju (KR): Korea Disease Control and Prevention Agency, 2020 [cited 2021 July 13]. Available from: http://www.cdc.go.kr/board.es?mi $\mathrm{d}=\mathrm{a} 20602010000$ \&bid=0034\&act=view\&list_no=366984\#.

19. Korea Disease Control and Prevention Agency. Quarantine System of Korean Government [Internet]. Cheongju (KR): Korea Disease Control and Prevention Agency, 2020 [cited 2021 July 13]. Available from: http://ncov.mohw. go.kr/en/baroView.do?brdId=11\&brdGubun=111\&dataGubun=\&ncvCont.

20. Kwon KT, Ko JH, Shin H, Sung M, Kim JY. Drive-through screening center for COVID-19: a safe and efficient screening system against massive community outbreak. J Korean Med Sci 2020;35:e123.

21. Korean Society of Infectious Diseases; Korean Society of Pediatric Infectious Diseases; Korean Society of Epidemiology; Korean Society for Antimicrobial Therapy; Korean Society for Healthcare-associated Infection Control and Prevention; Korea Centers for Disease Control and Pre- 
vention. Report on the epidemiological features of coronavirus disease 2019 (COVID-19) outbreak in the Republic of Korea from January 19 to March 2, 2020. J Korean Med Sci 2020;35:e112.

22. Jung H, Kim JK, Lee S, et al. Comparison of filtration efficiency and pressure drop in anti-yellow sand masks, quarantine masks, medical masks, general masks, and handkerchiefs. Aerosol Air Qual Res 2014;14:991-1002.

23. Jacobs SE, Lamson DM, St George K, Walsh TJ. Human rhinoviruses. Clin Microbiol Rev 2013;26:135-162.

24. Jefferson T, Del Mar CB, Dooley L, et al. Physical interventions to interrupt or reduce the spread of respiratory viruses. Cochrane Database Syst Rev 2011;2011:CDoo6207.

25. Leung NHL, Chu DKW, Shiu EYC, et al. Respiratory virus shedding in exhaled breath and efficacy of face masks. Nat Med 2020;26:676-680.

26. Jefferson T, Del Mar C, Dooley L, et al. Physical interventions to interrupt or reduce the spread of respiratory viruses: systematic review. BMJ 2009;339:b3675.

27. Aiello AE, Murray GF, Perez V, et al. Mask use, hand hygiene, and seasonal influenza-like illness among young adults: a randomized intervention trial. J Infect Dis 2010;201:491-498.

28. Cowling BJ, Chan KH, Fang VJ, et al. Facemasks and hand hygiene to prevent influenza transmission in households: a cluster randomized trial. Ann Intern Med 2009;151:437446.

29. Larson EL, Ferng YH, Wong-McLoughlin J, Wang S, Haber M, Morse SS. Impact of non-pharmaceutical interventions on URIs and influenza in crowded, urban households. Public Health Rep 2010;125:178-191.

30. MacIntyre CR, Cauchemez S, Dwyer DE, et al. Face mask use and control of respiratory virus transmission in households. Emerg Infect Dis 2009;15:233-241.

31. Lee $\mathrm{H}$, Lee $\mathrm{H}$, Song $\mathrm{KH}$, et al. Impact of public health interventions on seasonal influenza activity during the SARS-CoV-2 outbreak in Korea. Clin Infect Dis Clin Infect Dis 2021;73:e132-e140.

32. MacIntyre CR, Wang Q, Rahman B, et al. Efficacy of face masks and respirators in preventing upper respiratory tract bacterial colonization and co-infection in hospital healthcare workers. Prev Med 2014;62:1-7.

33. He X, Lau EHY, Wu P, et al. Temporal dynamics in viral shedding and transmissibility of COVID-19. Nat Med 2020;26:672-675.

34. Mizumoto K, Kagaya K, Zarebski A, Chowell G. Estimating the asymptomatic proportion of coronavirus disease 2019 (COVID-19) cases on board the Diamond Princess cruise ship, Yokohama, Japan, 2020. Euro Surveill 2020;25:2000180.

35. Price RHM, Graham C, Ramalingam S. Association between viral seasonality and meteorological factors. Sci Rep 2019;9:929.

36. Park J. Changes in subway ridership in response to COVID-19 in Seoul, South Korea: implications for social distancing. Cureus 2020;12:e7668.

37. Zhang N, Jia W, Lei H, et al. Effects of human behaviour changes during the COVID-19 pandemic on influenza spread in Hong Kong. Clin Infect Dis 2020 Dec 4 [Epub]. https://doi.org/10.1093/cid/ciaa1818.

38. Leung K, Wu JT, Liu D, Leung GM. First-wave COVID-19 transmissibility and severity in China outside Hubei after control measures, and second-wave scenario planning: a modelling impact assessment. Lancet 2020;395:1382-1393.

39. Sridhar D, Majumder MS. Modelling the pandemic. BMJ 2020;369:m1567. 


\section{APPENDIX 1. Online questionnaire}

Online questionnaire: preventive measure against COVID-19 infection

\#1. What is your sex?

Male / Female

\#2. What is your age?

$18-29 / 30-39 / 40-49 / 50-59 / 60-69 / \geq 70$

\#3. Are you a health-care worker (hospital or clinics, all kinds of workers)?

Yes / No

\#4. Do you think it is necessary to wear a mask regularly to protect yourself against the virus?

Yes/ No

\#5. Do you think people wearing masks may be sick patients?

Yes / No

We will ask the same questions for 'before' and 'during the COVID-19 epidemic.' Please answer separately. The questions below require one response per row.

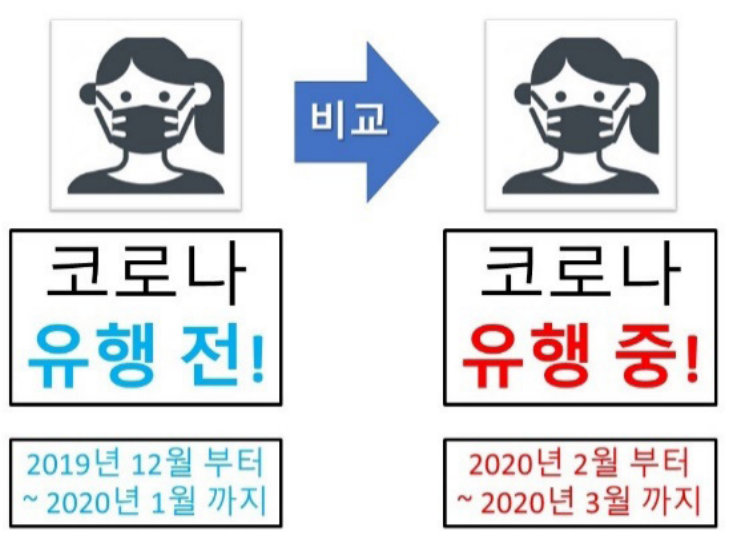

The period before the COVID-19 epidemic: from December 2019 to January 2020.

The period during and after the COVID-19 epidemic: from February 2020 to March 2020.

\#6. Overall, $d$ id you wear a mask during regular outings or at work?

Before epidemic: a. Never b. Seldom c. Generally d. Always

After epidemic: a. Never b. Seldom c. Generally d. Always

\#7. Did you wear a mask in public transportation?

Before epidemic: a. Never b. Seldom c. Generally d. Always

After epidemic: a. Never b. Seldom c. Generally d. Always 
\#8. Did you wear a mask in public indoor spaces with other people?

Before epidemic: a. Never b. Seldom c. Generally d. Always

After epidemic: a. Never b. Seldom c. Generally d. Always

\#9. Which masks did you most use?

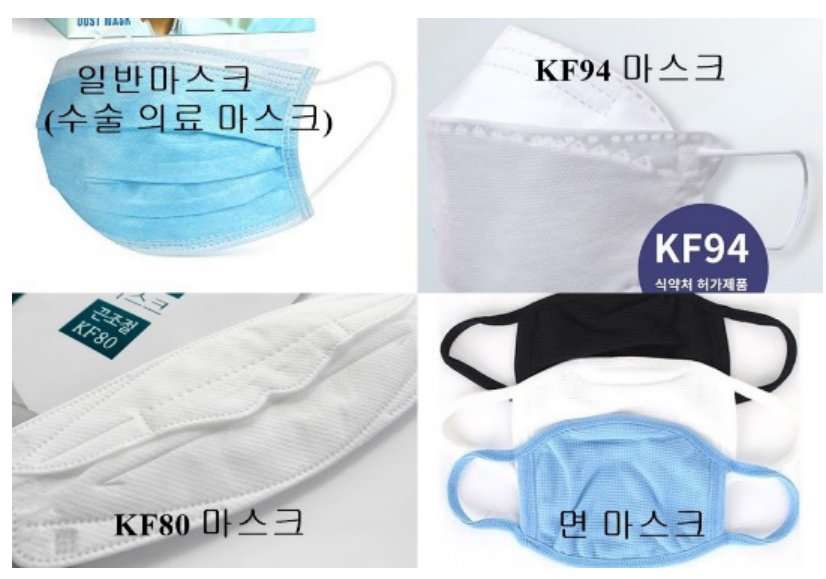

Before epidemic: a. Surgical mask b. KF94 c. KF8o d. Cotton mask e. Others

After epidemic: a. Surgical mask b. KF94 c. KF8o d. Cotton mask e. Others

\#10. Why did you use masks during the COVID-19 epidemic? (multiple choices are possible.)

a. For personal protection from the infection

b. To prevent infection of people around me

c. Because everyone else wears them and I did want to be singled out for not wearing them

d. It is necessary during work

e. Other reasons

\#11. Did you adhere to proper cough etiquette?

[Proper Coughing Etiquette]

Cover your mouths and nose with a tissue or your sleeve when coughing or sneezing. Wash your hands with soap after coughing or use a hand sanitiser.

Before epidemic: a. Never b. Seldom c. Generally d. Always

After epidemic: a. Never b. Seldom c. Generally d. Always

\#12. Did you adhere to correct hand-washing?

[Proper Wand-washing]

Wash your hands with running water and soap for at least 30 seconds. You could use an alcohol-based hand sanitiser. Palms - Backs of the hands - Between the fingers - Fingers interlocked - Thumbs - Under the nails

Before epidemic: a. Never b. Seldom c. Generally d. Always

After epidemic: a. Never b. Seldom c. Generally d. Always

\#13. How many times a day did you do accurate and correct hand-washing?

Before epidemic: a. o b. $1-5$ c. $6-10$ d. $>10$

After epidemic: a. o b. $1-5$ c. $6-10$ d. $>10$ 


\section{APPENDIX 2. Summary of the COVID-19 epidemic in South Korea}

The first case of coronavirus disease 2019 (COVID-19) in Korea was a 35-year-old woman who was living in Wuhan, China and had entered Korea on January 19, 2020 [11]. Subsequently, there was a continuous influx of COVID-19-positive patients into Korea; thus, the Korean government banned entry from the entire Hubei province in China on February 4, 2020. Additional COVID-19 cases were identified by further foreign influx and sporadic secondary contacts with traceable epidemiology and contacts. However, after February 18, 2020 the number of infected cases dramatically increased following large-scale gatherings of religious groups in Daegu. The nationwide quarantine system was strengthened and expanded, and the number of confirmed patients increased with the increase in COVID-19 testing through conventional screening clinics, as well as 'Drive Thru' or 'Walk Thru' centers [18-21].

A total of 10,708 patients were confirmed COVID-19 positive as of April 24, 2020. The total cumulative positive ratio of the test was $1.8 \%$. Among confirmed patients, $59.6 \%$ were women and $40.4 \%$ were men. The average age of confirmed patients was 44 years old, and by age group, those in their $20 \mathrm{~s}$ (20 to 29) had the highest number of cases (27.4\%), and 2,538 (23.7\%) were over 60 years old. The overall mortality rate was $2.2 \%$, and the mortality rate for patients over 80 years old was $23.5 \%$. The average duration of the diagnosis for 7,367 patients with confirmed symptom onset was 4.7 days on average. The pattern of occurrence of COVID-19 infection in Korea is that the disease widely spread around specific religious groups (Shincheonji) in Daegu, and the area accounted for $63.9 \%$ of all confirmed cases in Korea. Overall, 5,212 $(48.7 \%)$ cases were correlated with a religious group, $3,290(30.7 \%)$ cases were sporadic or from small clusters of infections in the community, and 1,023 (9.5\%) cases were estimated to be from overseas. The predominance of cases in the 20 s and females were likely caused by the outbreak related to a religious group in Daegu [21]. 
Supplementary Table 1. Individual preventive measures and the type of mask used, before and after the COVID-19 epidemic in an online survey in South Korea

\begin{tabular}{|c|c|c|c|}
\hline \multirow[b]{2}{*}{ Individual preventive measures } & \multicolumn{2}{|c|}{ Response frequency $(\mathrm{n}=604)$} & \multirow[b]{2}{*}{$p$ value ${ }^{b}$} \\
\hline & $\begin{array}{c}\text { Before COVID-19 } \\
2019.12-2020.1^{\mathrm{a}}\end{array}$ & $\begin{array}{l}\text { After COVID-19 } \\
2020.2-2020.3^{a}\end{array}$ & \\
\hline Wearing a mask during regular outings or at work ${ }^{\mathrm{c}}$ & & & $<0.001$ \\
\hline Never, 1 point & $327(54 \cdot 1)$ & $4(0.7)$ & \\
\hline Seldom, 2 point & $203(33.6)$ & $24(4 \cdot 5)$ & \\
\hline Generally, 3 point & $61(10.1)$ & $210(34.8)$ & \\
\hline Always, 4 point & $13(2.2)$ & $363(60.1)$ & \\
\hline Mean of points & $1.60 \pm 0.76$ & $3.54 \pm 0.61$ & \\
\hline Wearing a mask in public transportation $(n=598)^{d}$ & & & $<0.001$ \\
\hline Never, 1 point & $374(62.5)$ & $5(0.8)$ & \\
\hline Seldom, 2 point & $161(26.9)$ & $6(1.0)$ & \\
\hline Generally, 3 point & $40(6.7)$ & $92(15 \cdot 4)$ & \\
\hline Always, 4 point & $23(3.8)$ & $495(82.8)$ & \\
\hline Mean of points & $1.52 \pm 0.78$ & $3.80 \pm 0.48$ & \\
\hline Wearing a mask in public indoor space with other people & & & $<0.001$ \\
\hline Never, 1 point & $375(62.1)$ & $5(0.8)$ & \\
\hline Seldom, 2 point & $168(27.8)$ & $10(1.7)$ & \\
\hline Generally, 3 point & $44(7 \cdot 3)$ & $114(18.9)$ & \\
\hline Always, 4 point & $17(2.8)$ & $475(78.6)$ & \\
\hline Mean of points & $1.51 \pm 0.75$ & $3.75 \pm 0.52$ & \\
\hline Adhering to correct cough etiquette $\mathrm{e}^{\mathrm{e}}$ & & & $<0.001$ \\
\hline Never, 1 point & $65(10.8)$ & $4(0.7)$ & \\
\hline Seldom, 2 point & $199(32.9)$ & $21(3 \cdot 5)$ & \\
\hline Generally, 3 point & $232(38.4)$ & $198(32.8)$ & \\
\hline Always, 4 point & $108(17.9)$ & $381(63.1)$ & \\
\hline Mean of points & $2.63 \pm 0.90$ & $3.58 \pm 0.59$ & \\
\hline Adhering to correct hand-washing ${ }^{\mathrm{e}}$ & & & $<0.001$ \\
\hline Never, 1 point & $35(5.8)$ & $4(0.7)$ & \\
\hline Seldom, 2 point & $212(35 \cdot 1)$ & $20(3 \cdot 3)$ & \\
\hline Generally, 3 point & $260(43.0)$ & $231(38.2)$ & \\
\hline Always, 4 point & $97(16.1)$ & $349(57.8)$ & \\
\hline Mean of points & $2.69 \pm 0.80$ & $3.53 \pm 0.60$ & \\
\hline Correct hand-washing number ${ }^{f}$ & & & $<0.001$ \\
\hline o (not done), 1 point & $36(6.0)$ & $3(0.5)$ & \\
\hline 1-5 times, 2 point & $387(64.1)$ & $146(24.2)$ & \\
\hline 6-10 times, 3 point & $140(23.2)$ & $276(45 \cdot 7)$ & \\
\hline More than 10 times, 4 point & $41(6.8)$ & $179(29.6)$ & \\
\hline Mean of points & $2.31 \pm 0.68$ & $3.04 \pm 0.75$ & $<0.001$ \\
\hline Most used mask & & & - \\
\hline Surgical mask & $279(46.2)$ & $75(12.4)$ & \\
\hline
\end{tabular}


Park JY, et al. Respiratory virus, COVID-19 pandemic

Supplementary Table 1. Continued

\begin{tabular}{lcc}
\hline \multirow{2}{*}{ Individual preventive measures } & \multicolumn{2}{c}{ Response frequency $(\mathrm{n}=604)$} \\
\cline { 2 - 3 } & $\begin{array}{c}\text { Before COVID-19 } \\
2019.12-2020.1^{\mathrm{a}}\end{array}$ & $\begin{array}{c}\text { After COVID-19 } \\
2020.2-2020.3^{\mathrm{a}}\end{array}$
\end{tabular} pvalue $^{\mathrm{b}}$

Values are presented as number (\%) or mean \pm standard deviation.

COVID-19, coronavirus disease 2019.

${ }^{\mathrm{a}}$ For the survey, the cut-off day of the COVID-19 epidemic was defined as January 31, 2020. On January 27, the national infectious disease alert level went from 'caution' to 'alert.' To reduce recall bias, data was divided into monthly units.

${ }^{\mathrm{b}}$ Comparison of mask use and personal hygiene before and after the COVID-19 epidemic was analyzed by paired $t$ test.

'Likert scale responses: "Never," "Seldom," "Generally," "Always." Depending on the level of performance, the question was scored from 1 for 'Never' to 4 for 'Always.'

${ }^{\mathrm{d}}$ Data were missing for six patients. Except for this item, all respondents had to complete the mandatory answers when proceeding with the online surveys and submit the final responses. The answer data of the respondents who stopped in the middle of the questionnaire could not be collected.

${ }^{\mathrm{e}}$ Cover mouths and nose with tissue or elbow when coughing or sneezing. Wash hands with running water and soap or sanitiser for at least 30 seconds with six steps as Korean Centers for Disease Control and Prevention recommend.

${ }^{\mathrm{f}}$ Scoring of proper hand-washing: 1 point (not done); 2 points (1-5 times); 3 points (6-10 times); 4 points (more than 10 times).

${ }^{\mathrm{g}} \mathrm{KF}_{94}$ masks certified by the Korean Ministry of Food and Drug Safety (similar to FFP2) are suitable for healthcare workers as filtering facepiece masks. The performance, such as filtering efficiency, is almost identical between KF94 and N95 [22]. Korea government supply $\mathrm{KF}_{94}$ masks to the public (two masks per person per week). 
Supplementary Table 2. Masking (indoor space with other people) and hand-washing adherence before the COVID-19 outbreak

\begin{tabular}{|c|c|c|c|c|c|c|c|c|}
\hline \multirow[b]{2}{*}{ Variable } & \multicolumn{4}{|c|}{ Masking (public indoor places) } & \multicolumn{4}{|c|}{ Correct hand-washing practice } \\
\hline & $\begin{array}{l}\text { Never or } \\
\text { seldom }^{\text {a }}\end{array}$ & $\begin{array}{l}\text { Always or } \\
\text { generally }\end{array}$ & OR $(95 \% \mathrm{CI})$ & $p$ value & $\begin{array}{l}\text { Never or } \\
\text { seldom }^{a}\end{array}$ & $\begin{array}{l}\text { Always or } \\
\text { generally }^{\mathrm{a}}\end{array}$ & OR $(95 \% \mathrm{CI})$ & $p$ value \\
\hline \multicolumn{9}{|l|}{ Sex } \\
\hline Male & 219 & 21 & 1.0 & - & 118 & 122 & 1.0 & - \\
\hline Female & 324 & 40 & $1.29(0.74-2.24)$ & 0.372 & 129 & 235 & $1.76(1.26-2.46)$ & 0.001 \\
\hline \multicolumn{9}{|c|}{ Age group, yr } \\
\hline $18-49$ & 336 & 36 & 1.0 & - & 150 & 222 & 1.0 & - \\
\hline$\geq 50$ & 207 & 25 & $1.13(0.66-1.93)$ & 0.663 & 97 & 135 & $0.94(0.67-1.31)$ & 0.718 \\
\hline \multicolumn{9}{|c|}{ Occupation } \\
\hline Public & 507 & 58 & 1.0 & - & 235 & 330 & 1.0 & - \\
\hline HCWs & 36 & 3 & $0.73(0.22-2.44)$ & 0.787 & 12 & 27 & $1.60(0.79-3.23)$ & 0.184 \\
\hline
\end{tabular}

COVID-19, coronavirus disease 2019; OR, odds ratio; CI, confidence interval; HCW, health-care workers.

a Likert-type responses: "Never do," "Seldom do," "Generally do," "Always do." 
Park JY, et al. Respiratory virus, COVID-19 pandemic

Supplementary Table 3. Masking (indoor space with other people) and hand-washing adherence after the COVID-19 outbreak

\begin{tabular}{|c|c|c|c|c|c|c|c|c|}
\hline \multirow[b]{2}{*}{ Variable } & \multicolumn{4}{|c|}{ Masking (public indoor places) } & \multicolumn{4}{|c|}{ Correct hand-washing practice } \\
\hline & $\begin{array}{l}\text { Never or } \\
\text { seldom }^{\text {a }}\end{array}$ & $\begin{array}{l}\text { Always or } \\
\text { generally }^{\mathrm{a}}\end{array}$ & OR $(95 \% \mathrm{CI})$ & $p$ value & $\begin{array}{l}\text { Never or } \\
\text { seldom }^{a}\end{array}$ & $\begin{array}{l}\text { Always or } \\
\text { generally }^{\mathrm{a}}\end{array}$ & OR (95\% CI) & $p$ value \\
\hline \multicolumn{9}{|l|}{ Sex } \\
\hline Male & 12 & 228 & 1.0 & - & 19 & 221 & 1.0 & - \\
\hline Female & 3 & 361 & $6.33(1.77-22.69)$ & 0.002 & 5 & 359 & $6.17(2.27-16.77)$ & $<0.001$ \\
\hline \multicolumn{9}{|c|}{ Age group, yr } \\
\hline $1-49$ & 10 & 362 & 1.0 & - & 22 & 350 & 1.0 & - \\
\hline$\geq 50$ & 5 & 227 & $1.25(0.42-3.71)$ & 0.792 & 2 & 230 & $7.23(1.68-31.03)$ & 0.001 \\
\hline \multicolumn{9}{|c|}{ Occupation } \\
\hline Public & 12 & 553 & 1.0 & - & 22 & 543 & 1.0 & - \\
\hline HCWs & 3 & 36 & $0.26(0.07-0.96)$ & 0.066 & 2 & 37 & $0.75(0.17-3.31)$ & 0.468 \\
\hline
\end{tabular}

COVID-19, coronavirus disease 2019; OR, odds ratio; CI, confidence interval; HCW, health-care workers.

aikert-type responses: "Never do," "Seldom do," "Generally do," "Always do." 
Supplementary Table 4. Pearson's correlation coefficients for personal hygiene before the COVID-19 outbreak, South Korea

\begin{tabular}{|c|c|c|c|c|c|c|}
\hline Variable & $(1)$ & $(2)$ & (3) & (4) & $(5)$ & (6) \\
\hline (1) Wearing a mask during regular outings or at work & 1 & & & & & \\
\hline (2) Wearing a mask in public transportation & $0.802^{\mathrm{a}}$ & 1 & & & & \\
\hline (3) Wearing a mask in public indoor space with other people & $0.788^{\mathrm{a}}$ & $0.910^{\mathrm{a}}$ & 1 & & & \\
\hline (4) Adhering to correct cough etiquette & $0.223^{\mathrm{a}}$ & $0.260^{\mathrm{a}}$ & $0.229^{\mathrm{a}}$ & 1 & & \\
\hline (5) Adhering to correct hand-washing & $0.222^{\mathrm{a}}$ & $0.253^{\mathrm{a}}$ & $0.238^{\mathrm{a}}$ & $0.514^{\mathrm{a}}$ & 1 & \\
\hline (6) Hand-washing number & $0.134^{\mathrm{b}}$ & $0.135^{\mathrm{b}}$ & $0.143^{\mathrm{a}}$ & $0.332^{\mathrm{a}}$ & $0.564^{a}$ & 1 \\
\hline
\end{tabular}

COVID-19, coronavirus disease 2019.

${ }^{\mathrm{a}} \mathrm{p}<0.001$.

${ }^{\mathrm{b}} \mathrm{p}=0.001$. 
Park JY, et al. Respiratory virus, COVID-19 pandemic

Supplementary Table 5. Pearson's correlation coefficients for personal hygiene after the COVID-19 outbreak, South Korea

\begin{tabular}{|c|c|c|c|c|c|c|}
\hline Variable & $(1)$ & $(2)$ & (3) & (4) & $(5)$ & (6) \\
\hline (1) Wearing a mask during regular outings or at work & 1 & & & & & \\
\hline (2) Wearing a mask in public transportation & $0.554^{\mathrm{a}}$ & 1 & & & & \\
\hline (3) Wearing a mask in public indoor space with other people & $0.624^{\mathrm{a}}$ & $0.771^{\mathrm{a}}$ & 1 & & & \\
\hline (4) Adhering to correct cough etiquette & $0.363^{\mathrm{a}}$ & $0.365^{\mathrm{a}}$ & $0.365^{\mathrm{a}}$ & 1 & & \\
\hline (5) Adhering to correct hand-washing & $0.379^{\mathrm{a}}$ & $0.347^{\mathrm{a}}$ & $0.355^{\mathrm{a}}$ & $0.533^{\mathrm{a}}$ & 1 & \\
\hline (6) Hand-washing number & $0.251^{\mathrm{a}}$ & $0.207^{\mathrm{a}}$ & $0.256^{\mathrm{a}}$ & $0.349^{\mathrm{a}}$ & $0.498^{\mathrm{a}}$ & 1 \\
\hline
\end{tabular}

COVID-19, coronavirus disease 2019.

${ }^{\mathrm{a}} \mathrm{p}<0.001$.

${ }^{\mathrm{b}} \mathrm{p}=0.001$ 


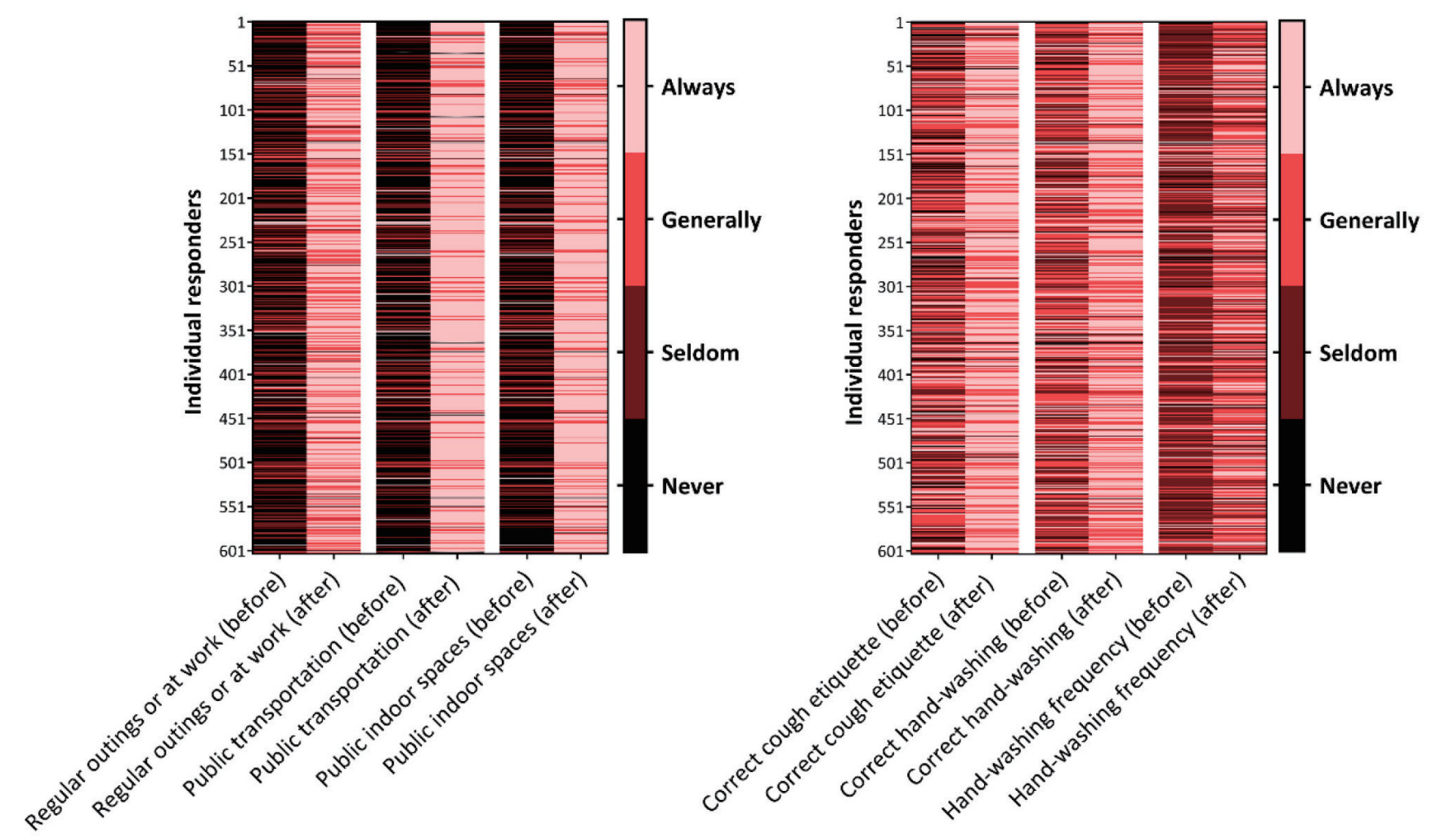

Supplementary Figure 1. Online survey results of individual preventive measures before and after the coronavirus disease 2019 (COVID-19) epidemic. (A) The paired responses of all survey subjects about universal masking and (B) coughing etiquette and hand-washing before and after the COVID-19 epidemic. A single thin horizontal box means one survey responder. The inner color of box is the answer to that question. 


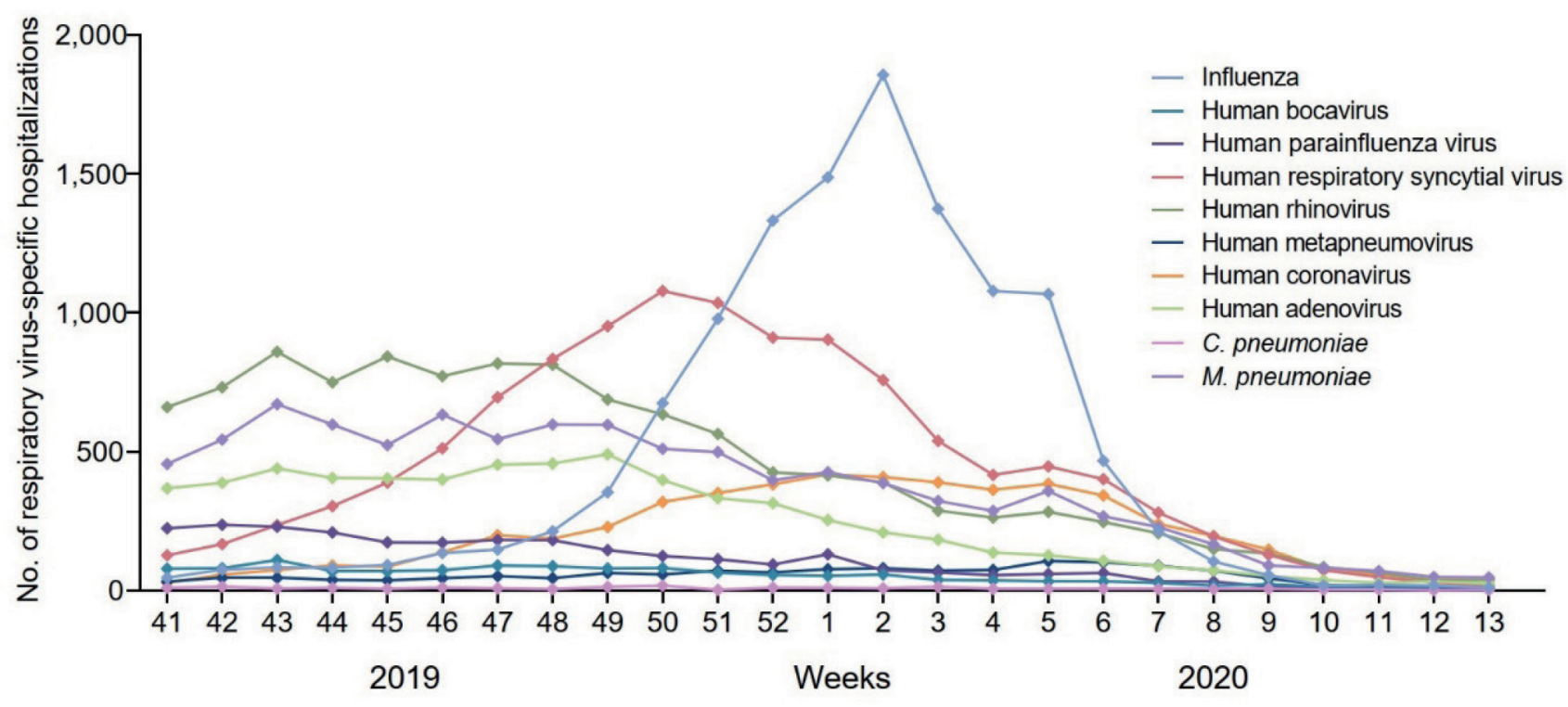

Supplementary Figure 2. Weekly change in the number of hospitalized adults with an acute respiratory viral infection. 